\title{
Factors influencing cognitive reactivity among young adults at high risk for depression in China: a cross- sectional study
}

fei fei huang ( $\sim$ pt860315@163.com )

Fujian Medical University https://orcid.org/0000-0003-0197-8687

\section{Zhi Peng Wen}

Affilicated hosptial of Putian University

qi li

900th Hospital of PLA

bin chen

fuzhou fourth hosptial

Wen Jie Weng

putian psychiatric hosptical

\section{Research article}

Keywords: Depression; Cognitive Reactivity; Young adults; Survey; China

Posted Date: April 15th, 2020

DOI: https://doi.org/10.21203/rs.2.18838/v3

License: (a) (i) This work is licensed under a Creative Commons Attribution 4.0 International License. Read Full License

Version of Record: A version of this preprint was published at BMC Public Health on May 15th, 2020. See the published version at https://doi.org/10.1186/s12889-020-08845-9. 


\section{Abstract}

Background: Understanding the factors influencing cognitive reactivity (CR) may help identify individuals at risk for first episode depression and relapse and facilitate routine access to preventative treatments. However, few studies have examined the relationship between CR and depression in Asian countries. This study was performed to assess the current status of $\mathrm{CR}$ among Chinese young adults and explore influencing factors.

Methods: A national cross-sectional online study using convenience sampling was conducted among 1597 healthy young adults in China (response rate: $93.94 \%)$ with a mean age of $24.34(S D=5.76)$ years.

Results: The mean CR score was $51.36 \pm 18.97$ (range 0-130). Binary logistic regression showed that a low level of $\mathrm{CR}$ was associated with the following factors: high self-compassion, high social support, high resilience, high monthly household income, and living in a rural area, with odds ratios (ORs) ranging from 0.14 to 0.70 . Young adults in full-time employment, experiencing poor sleep, with high neuroticism, who reported frequent sad mood, and who had a high intensity of negative life events had increased CR to depression, with ORs ranging from 1.18 to 6.66 . The prediction probability of these factors was $75.40 \%$. Causal relationships among the influencing factors and CR could not be explored.

Conclusions: The self-reported CR levels among Chinese young adults were moderate. Enhancing selfcompassion, resilience, and social support for young adults and reducing negative life events, neuroticism, and poor sleep may help decrease CR. These findings may help healthcare providers or researchers determine how to cultivate and improve the CR of young adults by establishing documented policies and/or improving intervention efficacies.

\section{Background}

Depression is one of the most prevalent psychological disorders worldwide and places a significant economic burden on society [1]. In 2016, it was ranked by the World Health Organization (WHO) as the single largest contributor to global disability [2]. Depression has historically been viewed as a condition affecting older adults [3]; however, many patients experience their first episode early in life. In recent years, young adults aged 18 to 35 years are increasingly recognized as a population group significantly affected by depression [3]. It is estimated that approximately $25 \%$ of young adults experience depressive symptoms and $2.5 \%$ of these meet the criteria for a major depressive episode, according to the Diagnostic and Statistical Manual for Mental Disorders (DSM-5) major depressive disorder (MDD) criteria [4].

Despite existing evidence-based treatments for major depression, it remains a chronic and recurrent illness, with $85 \%$ of people who experience a single episode experiencing another within 15 years [5]. High rates of depression that remain undetected further enhance its debilitating effects, with over $72.3 \%$ of individuals with depression not even being aware of their problem [6]. Globally, young adults are often overlooked, misdiagnosed, or undetected compared to older adults, possibly due to the uncertainties (e.g., initiating the roles and responsibilities of adulthood) young people experience being accompanied by irritability and mood fluctuations [7]. Among those who do not meet the diagnostic criteria for major depression, $10 \%$ to $35 \%$ experience episodes of low mood or sub-threshold depression that significantly impair their quality of life. These alarming statistics underscore the importance of identifying signs of depression in young adults and 
identifying those at risk of depression, which may provide clinical targets for depression prevention and early interventions [3].

The etiology of depression is complex, with no single underlying cause. According to Beck's cognitive model, individuals with depression typically experience cognitive distortions and dysfunctional attitudes and beliefs, which tend to decrease but can be reactivated by dysphoric mood. The ease with which such negative cognitions can be (re-)activated by sad mood states is referred to as cognitive reactivity (CR) [8]. In recent years, a promising line of research has highlighted the role of $\mathrm{CR}$ in the development, maintenance, and relapse/recurrence of depressive symptoms or clinical depression (e.g., [9-11]). Thus, the relevance of CR to depression should be further explored.

Understanding CR and its influencing factors may help target individuals at risk for the first episode and relapse of depression and increase access to preventive treatments, decreasing the personal and societal burdens of depressive disorders [5]. Previous studies have shown that CR can be directly and indirectly affected by some socio-demographic and psychosocial factors of mixed clinical/healthy individuals, including body mass index (BMI) for adolescents (weight in kilograms divided by the square of the person's height in meters $\left[\mathrm{kg} / \mathrm{m}^{2}\right]$ ) [12], depression status and number of previous episodes for recurrent MDD [13,14], neuroticism [15], negative life events [9], and rumination [16]. Interestingly, previous studies have mainly concentrated on aspects concerning negative psychological outcomes (e.g., neuroticism) and biological markers of vulnerability to depression $[5,17]$.

Few groups have examined the association between CR and positive psychological resources (e.g., resilience) [18] that are considered to protect individuals from depression. In the current study, we extended this knowledge of protective factors in depression to include personal factors (e.g., resilience, self-compassion) and interpersonal factors (e.g., social support), and explored the associations between these factors and CR.

The majority of studies on CR have been conducted in western countries, and relatively few have examined either the current status or related influencing factors (especially positive ones) of CR in Asian countries. However, cultural teachings often influence beliefs about the origins and nature of mental illness and shape attitudes towards the mentally ill [19]. CR findings from western countries may not directly apply to the Chinese context. For example, in China, where many cultures value "conformity to norms, emotional selfcontrol, [and] family recognition through achievement," depression is often stigmatized and seen as a source of shame [19].

The "Healthy China 2030" blueprint was proposed in 2017 by the Chinese government [20] based on four core principles: health priority, reform and innovation, scientific development, and justice and equity. It outlines 13 core indicators to be reported in 2020 and 2030. One was the improvement of mental healthcare and preventative services [21]. To help achieve this target, the dual purpose of this nationwide cross-sectional study was to: (a) describe the current status of $\mathrm{CR}$ among Chinese young adults at high risk for depression; (b) identify factors associated with CR.

\section{Methods}

2.1. Participants 
Between January 2018 and January 2019, a total of 1700 young adults, aged 18-35 years, were enrolled in the online national survey using a convenience sampling method. The popular Chinese online survey platform Wenjuanxing (http://www.wjx.cn) was used. The survey recruitment information was posted to six administrative regions in China, including the northeast, east, north, south-central, southwest, and northwest areas. First, the link for the online survey was sent to the research partners or friends who reside in six administrative regions by email. Then, they posted this link in different forums (e.g., QQ, WeChat). To excluded participants who have a diagnosis of mental illness, such as MDD, bipolar disorder, psychotic disorders, and others, the participants would be asked whether or not receiving a diagnosis of mental illness from a psychiatrist. The sample size was determined by the subject to item ratio of 5-10:1 [22], and the total number of survey items was 166.

\subsection{Measures}

\subsubsection{CR}

The modified Chinese version of the Leiden Index of Depression Sensitivity (LEIDS-RR-CV) is a 26-item selfreport measure of CR to sad mood [6]. Participants are asked to imagine the last time they felt a mild state of dysphoria, and then to indicate the degree to which a list of statements describes their typical cognitions and behaviors in response to a sad mood. The LEIDS-RR-CV contains 26 items from 5 subscales, including hopelessness/suicidality, acceptance coping, aggression, control/perfectionism, and avoidant coping. All of the items are rated using a 5-point Likert-scale $(0=$ not at all to $4=$ very strongly). Items are all positively worded for $\mathrm{CR}$, and the total score is obtained by summing the scores of all items. Considering the differences in the numbers of items among the five subscales, the average score for each subscale was calculated. A higher total score indicates stronger CR. In this study, the Cronbach's a coefficient was 0.95 for the overall scale. Huang et al. identified a cut-off score of 60 for LEIDS-RR-CV to screen for healthy individuals at risk for depression in China [6].

\subsubsection{Social support}

The Multidimensional Scale of Perceived Social Support (MSPSS) is a 12-item self-report scale used to measure perceived social support from family, friends, and significant others [23,24]. The scale employs a 7point rating scale ranging from 1 (very strongly disagree) to 7 (very strongly agree). The total scores of the scale range from 12-84, with higher scores indicating greater levels of social support. The social support is classified into low, middle, and high support levels according to the cut-off score ranges of the MSPSS of 12$36,37-60$, and 61-84, respectively [24]. In this study, the Cronbach's a coefficient was 0.97 for the overall scale.

\subsubsection{Neuroticism}

The Neuroticism Subscale of the Chinese Big Five Personality Inventory (NEO-CBF-PI) is the most comprehensive self-report questionnaire measuring the five dimensions of personality, including neuroticism. The CBF-PI consists of 40 items and has been extensively validated [25]. The 8-item neuroticism subscale of the CBF-PI is rated on a 6-point Likert scale (1-6), with the total score ranging from 8 to 48 . Higher scores are indicative of a higher level of neuroticism. Based on previous studies [25], levels of neuroticism are classified 
into high and low according to a cut-off score of 36 for the CBF-PI. In this study, the Cronbach's a coefficient was 0.87 for the NEO-CBF-PI.

\subsubsection{Resilience}

The Chinese version of the 14-item Resilience Scale (RS-14) developed by Wagnild and Young is one of the most reliable tools in measuring resilience in various age groups and different conditions [26,27]. It is composed of 14 items representing the "Personal Competence Factor" and "Acceptance of Self and Life Factor." Each item is graded from 1 (strongly disagree) to 7 (strongly agree). Graded items are summed to provide a total score, with lower scores indicating less resilience. According to the cut-off value of 74, resilience levels are classified into high and low [27]. The RS-14 has satisfactory internal consistency with Cronbach's a ranging from 0.87 to 0.91 , and stability with test-retest reliability ranged from 0.65 to 0.84 [26]. In this study, the Cronbach's a of the RS-14 was 0.96 .

\subsubsection{Self-compassion}

The Self-Compassion Scale (SCS) is the most commonly used scale to measure self-compassion at times of perceived difficulty [28]. It is composed of 26 items and 6 subscales, including self-kindness, self-judgment, common humanity, isolation, mindfulness, and over-identification. Each item rated on a 5-point Likert-type scale for frequency (1=almost never, $5=$ almost always). The total score is calculated with the average of the individual subscales, and all negatively scored items are transformed. Levels of self-compassion are classified high and low according to $75 \%$ of the total SCS scores $(130 * 0.75)$ as based on a previous study [29] (i.e., a score of 98). In this study, the Cronbach's a of the SCS was 0.77.

\subsubsection{Life events}

The 48-item Life Events Scale (LES) is used to evaluate negative and positive life events that have occurred during the previous year or longer, including family, work or study, and social events [30]. Each of the 48 life

event items was anchored to 4 questions: (i) when it happened, measured by "never," "in the past 1 month," "in the past 1 year or longer"; (ii) whether it was positive or negative for the target person; (iii) the impact on the target person's mental health, measured by a 5-point scale ranging from "no impact" to "very severe impact"; (iv) the duration of the event, measured by a 4-point scale ranging from " 3 months," " 6 months," " $\leq 1$ year" to "longer." The intensity score of each life event is calculated by the time when it happened (i) multiplied by the duration (iii) and impact (iv). The total intensities of positive and negative life events are summed by the intensity score of each positive or negative life event. Based on the 75\% value of this score [29], the total intensities of positive and negative life events are further classified into high and low levels. In this study, the Cronbach's a of the LES was 0.94 .

\subsubsection{Socio-demographic and clinical characteristics}

Participants were asked about their socio-demographics including residential area (northeast/ eastern/ north/ south central/ southwest/ northwest area), residential location (urban/suburban/rural), age, sex (male/female), marital status (married/ unmarried/ others), educational level (less than high school degree/high school degree /bachelor's degree or higher), religious belief (no/ yes), monthly household income 
(Yuan, RMB)(<1000/1000-2999/3000-4999/5000+), employment status (students/ full-time employment/ unemployment/ farmer/ other), and living mode (living by oneself/ living with spouse/ living with family/ others).

We also collected clinical characteristics including smoking status(yes/no), BMI, family history of mental illness (no/yes/unclear), whether they had previously experienced depression (yes/no), the frequency of sad mood in the past month (none/ occasionally/ sometimes/ often/ always), and their sleep quality (very good/ good/ average/ bad/ very bad). In this study, according to the WHO-recommended BMI cut-off values for adults [31], BMl is classified as underweight, $\mathrm{BMI}<18.5 \mathrm{~kg} / \mathrm{m}^{2}$; normal weight, $\mathrm{BMI} 18.5$ to $25.0 \mathrm{~kg} / \mathrm{m}^{2}$; and overweight, $\mathrm{BMI} \geq 25.0 \mathrm{~kg} / \mathrm{m}^{2}$.

\subsection{Procedure}

All procedures were approved by the ethical committee of Fujian Medical University (No. FMU2017024), and informed consent was obtained from all participants. The study adhered to the STROBE (Strengthening the Reporting of Observational studies in Epidemiology) statement [32]. All measures were completed via the Wenjuanxing platform. The participants read and signed the written informed consent form on the platform before they completed the questionnaire in approximately 20-30 min. The questionnaire could not be submitted if it was less than half complete or contained repeated answers. Participants who completed the survey were remunerated with a RMB 10 gift card.

\subsection{Statistical analysis}

Data analyses were conducted using SPSS 24.0 (IBM, Armonk, NY, USA). Approximately 5\% of missing data were replaced using mean value substitution, and $p<0.05$ was considered statistically significant. The data met the assumptions of normality as one-sample Kolmogorov-Smirnov tests were not statistically significant. Continuous variables are expressed as means and standard deviations (SDs) and were dichotomized to improve comparison [33]. Categorical variables are expressed as proportions or percentages.

Young adults with a LEIDS-RR-CV total score $<60$ were considered the normal group (NG), while those with a score $\geq 60$ were considered the risk for depression group (RDG).

We performed three analysis steps to identify influencing factors of CR. First, chi-square tests were used to compare the differences in socio-demographic and clinical variables, self-compassion, resilience, social support, neuroticism, and life events between the two groups. Second, the collinearity of the independent variables was examined by the variance inflation factor (VIF) before conducting binary logistic regression. The VIFs of the 11 variables ranged from $0.45-2.63$ (ideal is $<4.0$ ), suggesting no violations of the regression assumptions [34].

Third, binary logistic regression with a forward conditional method was conducted to determine the influencing factors associated with CR. There is evidence in the logistic regression literature that backward selection is often less successful than forward selection because the full model fit in the first step is the model most likely to result in a complete or quasi-complete separation of response values [35]. The dependent 
variable was whether the young adults were at risk for depression. The variables that were statistically significant in chi-square tests were input as independent variables.

\section{Results}

A total of 1597 valid questionnaires were returned out of the 1700 questionnaires distributed (response rate, 93.94\%). Specifically, the response rate for the northeast, east, north, south-central, southwest, and northwest areas was $92.85 \%, 91.66 \%, 96.74 \%, 95.84 \%, 91.83 \%, 94.73 \%$, respectively. The mean age of young adults was 24.34 years $(S D=5.76)$, and the average BMI was $22.21 \mathrm{~kg} / \mathrm{m}^{2}(\mathrm{SD}=6.54)$. Table 1 shows the sociodemographic characteristics of all participants.

\subsection{CR scores of the young adults}

The participants were classified into two NG and RDG according to the LEIDS-RR-CV cut-off score. In total, there has 494 young adults (30.93\%) in RDG, and 1103 young adults $(69.07 \%)$ in NG. As shown in Table 2, the total mean scores for the LEIDS-RR-CV in Chinese young adults were 51.36 \pm 18.97 (range 0-130) overall, $41.30 \pm 11.80$ (range $0-59$ ) for the NG, and 73.82 \pm 11.07 (range 60-130) for the RDG. The highest and lowest mean scores were for avoidant coping $(2.24 \pm 0.86)$ and hopelessness/suicidality $(1.73 \pm 0.93)$, respectively. Furthermore, there were statistically significant differences in the total and sub-scale scores between the NG and RDG (see Table 2).

\subsection{Factors associated with $\mathrm{CR}$ in young adults at risk for depression}

As shown in Table 1, the differences in residential area and location, monthly household income, employment status, family history of mental illness, frequency of sad mood in the past month, and sleep quality between groups were all statistically significant $(p<0.05)$. Table 1 also shows that young adults in the NG had higher levels of self-compassion, resilience, and social support and had experienced more positive life events than those in the RDG $(p<0.05)$. The levels of neuroticism and negative life events for young adults in the RDG were higher compared to individuals in the NG $(p<0.05)$.

The predictors of $\mathrm{CR}$ determined using binary logistic regression are shown in Table 3. The analysis indicated that the main predictors influencing $\mathrm{CR}$ were high levels of self-compassion, followed by residence in a rural location, having high social support, resilience, and high monthly household income. For example, participants with high self-compassion were 0.14 times likely to report $C R$ to depression than individuals with low selfcompassion (odds ratio [OR] $=0.14,95 \%$ confidence interval $[\mathrm{Cl}] 0.05-0.71$ ).

In contrast, young adults with a high level of neuroticism, followed by those with frequent sad mood in the past month, in full-time employment, having a high intensity of negative life events, and bad sleep quality had higher $\mathrm{CR}$ to depression. For example, the risk of CR to depression in young adults with higher neuroticism was 6.66 times higher than for those with lower neuroticism ( $\mathrm{OR}=6.66,95 \% \mathrm{Cl} 1.41-3.33)$. The overall prediction probability of these factors was $75.40 \%$.

\section{Discussion}


The psychological well-being of young people has became a public health concern worldwide [36]. This population is vulnerable to psychological distress, and in particular, depression. Screening at-risk populations and providing targeted measures are cost-effective strategies to prevent and treat depression [6].

To our knowledge, this is the first study to explore the relationship between CR and depression and the associated influencing factors in young adults in China. The results revealed moderate levels of self-reported $\mathrm{CR}$ among Chinese young adults. Although the same instrument was used (LEIDS), our findings were still higher than in a population of mixed clinical/healthy individuals in the Netherlands [37] and a Spanish mixedpopulation [38], and slightly lower than non-depressed Iranian individuals [39] and recurrently depressed patients in remission in the Netherlands [5]. These disparities could be attributable to sociocultural aspects differences and the utilization of or access to mental health services differences for Asian and western countries, which needed to be further explored [19].

In this study, the CR levels of Chinese young adults were mainly reflected in terms of avoidant coping and control/perfectionism, both of which are closely linked to depression. For example, the highest score for avoidant coping indicates that when young individuals were under stress, they generally applied a maladaptive coping mechanism characterized by cognitive and behavioral efforts to deny, minimize, or avoid dealing with the situation. Although previous research has implicated CR both in the first episode and relapse of depression, the influencing factors or predictors of CR were unknown. Our findings provide the first evidence regarding factors associated with reduced or increased CR in Chinese young adults.

\subsection{Factors associated with reduced $C R$}

In our study, self-compassion and resilience were negatively associated with CR. Kuyken et al. also found an association between $\mathrm{CR}$ and self-compassion skills [40]. This may be due to self-compassion and resilience both being important protective factors against depression. Higher levels of self-compassion and resilience are typically related to greater psychological health, demonstrated through lower levels of depression and anxiety $[36,41]$. In other words, young individuals with higher self-compassion and resilience might be more likely to hold their feelings of suffering with a sense of warmth, connection, and concern, while negotiating, managing, and adapting to significant sources of stress and trauma [36].

Consistent with a previous study [42], we also found that lack of social support was significantly associated with CR. Support from family members, friends, or other people is particularly important for those experiencing stress [42]. This may explain why the level of CR among young adults with stronger social support was significantly lower than those with weaker social support.

As Zeng and Jian reported [43], the prevalence of depression can be directly and indirectly affected by socioeconomic status and inequality among different residential locations in China. Our study also found relationships between monthly household income, residential location, and CR with depression. Compared with young adults living in rural areas, CR was higher in young adults living in urban areas. Generally, people residing in cities experience higher stress and more challenges. If they cannot mitigate these, they become more prone to dysfunctional attitudes and depression. Furthermore, our study further confirms and adds to the growing body of evidence that poor economic conditions are strongly link with greater depressive symptoms [44]. In this study, individuals with a high monthly household income had lower CR, suggesting that the risk of 
depression among young adults may be decreased by reducing the psychosocial stress associated with financial hardship [44].

\subsection{Factors associated with increased $C R$.}

In line with other studies $[15,45]$, we also found that neuroticism and poor sleep quality were positively correlated with $\mathrm{CR}$ in Chinese young adults. In other words, individuals with higher neuroticism and poorer sleep quality were more likely to respond to mildly negative moods by reactivating thoughts relating to hopelessness (or other negative states), which are in turn, related with depression. Our analysis also revealed that $\mathrm{CR}$ among young adults was associated with an increased frequency of sad mood in the past month. The current study also confirms the association between negative life events and the prevalence of depression; when young adults encounter negative life events, they report less happiness and optimism, which may lead to poorer mental health [32]. Employment status was also identified as a risk factor associated with increased CR. That is, young adults in full-time employment encountered greater work-related stress or propensity to depression than students[7,29].

To effectively reduce the prevalence of depression, healthcare providers need to pay attention to factors associated with reduced or increased $\mathrm{CR}$, which is an important predictor of an episode of depression. By being aware of these potentially influencing factors on $\mathrm{CR}$, we can take targeted measures to reduce $\mathrm{CR}$ among young adults by enhancing their self-compassion, resilience, and social support; improving the quality of their sleep; and decreasing their neuroticism and experience of negative life events. For example, employing mindful intervention strategies to decrease neuroticism and problems with emotion regulation. We should pay special attention to young adults with high levels of $\mathrm{CR}$, who reside in urban areas, have low monthly household income, and are employed full time.

\subsection{Limitations}

Although this study revealed important findings, the results should be interpreted in the context of its limitations. First, the convenience sampling method and recruitment of non-clinical young adults may impact the generalization of the findings. Moreover, the mental illness diagnosis was self-reported by participants, which may have affected its accuracy. Second, the subjectivity associated with the use of self-reported questionnaires may also pose limitations, and our findings should be confirmed by objective measurements in the future, such as clinician-administered assessments. Third, the underlying causal relationships and effect mechanisms between the risk factors and CR were not examined. Future longitudinal or interventional research is needed to address this important issue.

\section{Conclusions}

The self-reported CR levels in Chinese young adults were moderate. Self-compassion, resilience, social support, and high monthly household income were identified as factors associated with lower $\mathrm{CR}$, while negative life events, neuroticism, and poor sleep quality were associated with higher CR. Young adults who were residents in urban areas, in full-time employment, and frequently experienced sad mood were at risk for high levels of CR. These findings may help healthcare providers and/or researchers design interventions to cultivate resilience and improve the $\mathrm{CR}$ of young adults. 


\section{Abbreviations}

$\mathrm{BMI}$, body mass index; $\mathrm{Cl}$, confidence interval; $\mathrm{CR}$, cognitive reactivity; LEIDS-RR-CV, Chinese version of the Leiden Index of Depression Sensitivity; LES, Life Events Scale; MDD, major depressive disorder; MSPSS, Multidimensional Scale of Perceived Social Support; NEO-CBF-PI, Neuroticism Subscale of the Chinese Big Five Personality Inventory; NG, normal group; OR, odds ratio; RDG, risk for depression group; RS-14, Chinese version of the 14-item Resilience Scale; SCS, Self-Compassion Scale; VIF, variance inflation factor; WHO, World Health Organization

\section{Declarations}

\section{Ethics approval and consent to participate}

Before survey, all participants were obtained by written informed consent. The research was approved by the Institutional Review Boards of Fujian Medical University in March 2017(NO: FMU2017024).

\section{Consent for publication}

Not applicable.

\section{Availability of data and materials}

The original data are available on request to the corresponding author, after the manuscript published. Whatever, we also considered to provide the original data in public repositories.

\section{Competing interests}

The authors declare that they have no competing interests.

\section{Funding}

This study was supported by a grant from the Natural Science Foundation of Fujian Province, China (Grant No. 2017J05133) , Startup Fund for scientific research, Fujian Medical University (Grant No. 2016QH017), and Startup Fund for High-level talents of Fujian Medical University (Grant No. XRCZX2017011).

\section{Authors' contributions}

Fei Fei Huang is the correspondence author of this study, responsible for designing, guiding, organizing and planning this study.

Zhi Peng Wen and Qi Li provided feedback, review the manuscript to aid in revisions, and contributed data.

Wen Jie Weng and Bin Chen are responsible for data collection and evaluation.

\section{Acknowledgements}


The authors would like to thank the healthy individuals and remission depression patients who participated in this study.

\section{References}

1. Smith K. Mental health: A world of depression. Nature. 2014;515(7526):181.

2. World Health Organization. 2016. http://www.who.int/mediacentre/factsheets/fs369/en/

3. Mętel D, Arciszewska A, Daren A, Frydecka D, Cechnicki A, Gawęda Ł. Resilience and cognitive biases mediate the relationship between early exposure to traumatic life events and depressive symptoms in young adults. J Affect Disord. 2019;254:26-33.

4. Hasin DS, Sarvet AL, Meyers JL, Saha TD, Ruan WJ, Stohl M, Grant BF. Epidemiology of adult DSM-5 major depressive disorder and its specifiers in the United States. JAMA Psychiatry.2018;75(4):336-346.

5. Figueroa CA, Mocking RJT, Mahmoud GA, Koeter MW, Bockting CL, Van der Does W, Ruhe HG, Schene AH. The measurement of cognitive reactivity to sad mood in patients remitted from major depressive disorder. Br J Clin Psychol. 2018;57(3):313-27.

6. Huang FF, Li H, Lei Y, Li Q, Chen B. Adaptation and validation of the Chinese version of the modified Leiden index of depression sensitivity. J Affect Disord. 2019;256:458-67. doi:10.1016/j.jad.2019.06.022.

7. Moreh S, O'Lawrence H. Common risk factors associated with adolescent and young adult depression. J Health Hum Serv Adm. 2016;39(2):283-310.

8. Van der Does W. Cognitive reactivity to sad mood: Structure and validity of a new measure. Behav Res Ther. 2002;40(1):105-20.

9. Struijs SY, Groenewold NA, Oude Voshaar RC, de Jonge P. Cognitive vulnerability differentially predicts symptom dimensions of depression. J Affect Disord. 2013;151(1):92-9.

10. Antypa N, Van der Does AJ, Penninx BW. Cognitive reactivity: Investigation of a potentially treatable marker of suicide risk in depression. J Affect Disord. 2010;122(1-2):46-52.

11. Wang YY, Li XH, Zheng W, Xu ZY, Ng CH, Ungvari GS, Yua Z, Xiang YT. Mindfulness-based interventions for major depressive disorder: A comprehensive meta-analysis of randomized controlled trials. J Affect Disord. 2018;229:429-36.

12. Oddy WH, Allen KL, Trapp GSA, Ambrosini GL, Black, LJ, Huang RC, Rzehak P, Runions KC, Pan F, Beilin LJ, Mori TA. Dietary patterns, body mass index and inflammation: Pathways to depression and mental health problems in adolescents. Brain Behav Immun. 2018;69:428-39.

13. Jarrett RB, Minhajuddin A, Borman PD, Dunlap L, Segal ZV, Kidner CL, Friedman ES, Thase ME. Cognitive reactivity, dysfunctional attitudes, and depressive relapse and recurrence in cognitive therapy responders. Behav Res Ther. 2012;50(5):280-6.

14. Elgersma HJ, de Jong PJ, van Rijsbergen GD, Kok GD, Burger H, van der Does W, Penninx BW, Bockting CL. Cognitive reactivity, self-depressed associations, and the recurrence of depression. J Affect Disord. 2015;183:300-9.

15. Barnhofer T, Chittka T. Cognitive reactivity mediates the relationship between neuroticism and depression. Behav Res Ther. 2010;48(4):275-81. 
16. Moulds ML, Kandris E, Williams AD, Lang T, Yap C, Hoffmeister K. An investigation of the relationship between cognitive reactivity and rumination. Behav Ther. 2008;39(1):65-71.

17. Antypa N, Verkuil B, Molendijk M, Schoevers R, Penninx BWJH, Van der Does W. Associations between chronotypes and psychological vulnerability factors of depression. Chronobiol Int. 2017;34(8):1125-35.

18. Cladder-Micus MB, van Aalderen J, Donders ART, Spijker J, Vrijsen JN, Speckens AEM. Cognitive reactivity as outcome and working mechanism of mindfulness-based cognitive therapy for recurrently depressed patients in remission. Cogn Emot. 2018;32(2):371-8.

19. Gopalkrishnan N. Cultural diversity and Mental Health: considerations for Policy and Practice. Front Public Health.2018;6:179.

20. Li L, Fu H. China's health care system reform: Progress and prospects. Int J Health Plann Manage. 2017;32(3):240-53.

21. Chen P, Li F, Harmer P. Healthy China 2030: moving from blueprint to action with a new focus on public health. Lancet Public Health.2019;4(9):e447.

22. Streiner D, Norman GR. Health Measurement Scales: A Practical Guide to their Development and Use. 3rd ed. New York: Oxford Medical Publications; 2003.

23. Pedersen SS, Spinder H, Erdman RA, Denollet J. Poor perceived social support in implantable cardioverter defibrillator (ICD) patients and their partners: cross-validation of the multidimensional scale of perceived social support. Psychosomatics. 2009;50(5):461-7.

24. Jiang QJ. Perceived Social Support Scale. Chin J Behavioral Med Sci. 2001;10:41-3.

25. Wang MC, Dai XY, Yao SQ. Development of the Chinese Big Five Personality Inventory (CBF-PI) III: Psychometric Properties of CBF-PI Brief Version. Chin J Clin Psychology. 2011;19(4):454-7.

26. Wagnild GM, Young HM. Development and psychometric evaluation of the Resilience Scale. J Nurs Meas. 1993;1(2):165-78.

27. Tian J, Hong JS. Validation of the Chinese version of the resilience scale and its cutoff score for detecting low resilience in Chinese cancer patients. Support Care Cancer. 2013;21(5):1497-502.

28. Neff KD. The development and validation of a scale to measure self-compassion. Self and Identity 2003;2(3):223-50.

29. Fang H, Cui NX, Guo $\mathrm{CH}$, Cao FL. Cumulative effect of risk and protective factors of depression symptom in female medical college students. Chin Mental Health J. 2013;27(12):949-54.

30. Mo Q, Zhou L, He Q, Jia C, Ma Z. Validating the Life Events Scale for the Elderly with proxy-based data: A case-control psychological autopsy study in rural China. Geriatr Gerontol Int. 2019;19(6):547-51.

31. World Health Organization. Physical Status: The Use and Interpretation of Anthropometry: Report of a WHO Expert Committee. Geneva: World Health Organization, 1995. 452 p. (Technical report series no. 854).

32. von Elm E, Altman DG, Egger M, Pocock SJ, Gøtzsche PC, Vandenbroucke JP. STROBE Initiative. The Strengthening the Reporting of Observational Studies in Epidemiology (STROBE) Statement: guidelines for reporting observational studies. Int J Surg. 2014;12(12):1495-9.

33. DeCoster J, Iselin AM, Gallucci M. A conceptual and empirical examination of justifications for dichotomization. Psychol Methods.2009;14(4):349-66. 
34. Ma C. The prevalence of depressive symptoms and associated factors in countryside-dwelling older Chinese patients with hypertension. J Clin Nurs. 2018;27(15-16):2933-41.

35. Heinze G, Wallisch C, Dunkler D. Variable selection - A review and recommendations for the practicing statistician. Biom J. 2018;60(3):431-49.

36. Shi M, Liu L, Wang ZY, Wang L. The mediating role of resilience in the relationship between big five personality and anxiety among Chinese medical students: A cross-sectional study. PLoS One. 2015;10(3):e0119916.

37. Solis E, Antypa N, Conijn JM, Kelderman H, Van der Does W. Psychometric properties of the Leiden Index of Depression Sensitivity (LEIDS). Psychol Assess. 2017;29(2):158-71.

38. Senín-Calderón C, Perona-Garcelán S, Ruíz-Veguilla M, Rodríguez-Testal JF. Leiden Index of Depression Sensitivity-Revised (LEIDS-R): Spanish validation proposal. Int J Clin Health Psychol. 2017;17(2):139-50.

39. Ostovar S, Md Nor MB, Griffiths MD, Chermahini SA. Cognitive Reactivity: Cultural Adaptation and Psychometric Testing of the Persian Version of the Leiden Index of Depression Sensitivity Revised (LEIDSR) in an Iranian Sample. Int J Ment Health Addict. 2017;15(3):621-38.

40. Kuyken W, Watkins E, Holden E, White K, Taylor RS, Byford S, Evans A, Radford S, Teasdale JD, Dalgleish T. How does mindfulness-based cognitive therapy work? Behav Res Ther. 2010;48(11):1105-12.

41. Raes F, Pommier E, Neff KD, Van Gucht D. Construction and factorial validation of a short form of the SelfCompassion Scale. Clin Psychol Psychother. 2011;18(3):250-5.

42. Li C, Jiang S, Zhang X. Intergenerational relationship, family social support, and depression among Chinese elderly: A structural equation modeling analysis. J Affect Disord. 2019;248:73-80.

43. Zeng J, Jian W. Changes in income-related inequalities of depression prevalence in China: A longitudinal, population study. Soc Psychiatry Psychiatr Epidemiol. 2019;54(9):1133-42.

44. Zhang C, Xue Y, Zhao H, Zheng X, Zhu R, Du Y, Zheng J, Yang T. Prevalence and related influencing factors of depressive symptoms among empty-nest elderly in Shanxi, China. J Affect Disord. 2019;245:750-6.

45. Samaranayake CB, Arroll B, Fernando AT 3rd. Sleep disorders, depression, anxiety and satisfaction with life among young adults: A survey of university students in Auckland, New Zealand. N Z Med J. 2014;127(1399):13-22.

\section{Tables}

TABLE 1 Socio-demographic and clinical characteristics comparison of the NG and RDG 
Residential area

Northeast area

East area

North area

South-central area

Southwest area

Northwest area

Sex

Male

Female

Residential location

Urban

Suburban

Rural

Religious belief

No

Yes

Education level Less than high school degree

High school degree (including

technical training)

Bachelor's degree or higher

Monthly household income

(yuan, RMB)

$<1000$

1000-2999

3000-4999

$5000+$

Employment status

Students

Full-time employment

Unemployment

Farmer

Other (e.g., retired, homemaker)

Marital status

Married

Unmarried

Others (e.g., divorced, widowed)

Family history of mental illness

No

Unclear

Yes

Living mode

Living by oneself

Living with spouse

Living with family

Others

Smoking status

Yes

No

The frequency of sad mood in the past month

None

Occasionally

Sometimes

Often

Always

Sleep quality

Very good

Good

Average

Bad

Very bad

BMI $\left(\mathrm{kg} / \mathrm{m}^{2}\right)$

$<18.5$ (underweight)

18.5-24.9 (normal weight)

$\geq 25$ (overweight)

\begin{tabular}{|c|c|c|c|c|}
\hline $\begin{array}{l}12.52 \\
37.13 \\
14.84 \\
11.77 \\
10.46 \\
13.27\end{array}$ & $\begin{array}{l}120(10.89) \\
460(41.70) \\
127(11.51) \\
118(10.70) \\
117(10.60) \\
161(14.60)\end{array}$ & $\begin{array}{c}80(16.19) \\
133(26.92) \\
110(22.27) \\
70(14.17) \\
50(10.12) \\
51(10.33)\end{array}$ & 17.65 & $<0.001$ \\
\hline $\begin{array}{l}22.79 \\
77.21\end{array}$ & $\begin{array}{l}241 \text { (21.85) } \\
862(78.15)\end{array}$ & $\begin{array}{l}122(24.70) \\
372(75.30)\end{array}$ & 2.43 & 0.30 \\
\hline $\begin{array}{l}50.22 \\
10.90 \\
38.89\end{array}$ & $\begin{array}{l}524(47.51) \\
118(10.70) \\
461(41.79)\end{array}$ & $\begin{array}{c}278(56.28) \\
56(11.34) \\
160(32.38)\end{array}$ & 12.41 & $<0.001$ \\
\hline $\begin{array}{l}83.47 \\
16.53\end{array}$ & $\begin{array}{l}926(83.95) \\
177(16.05)\end{array}$ & $\begin{array}{c}407(82.39) \\
87(17.61)\end{array}$ & 0.73 & 0.39 \\
\hline $\begin{array}{c}4.44 \\
10.71\end{array}$ & $\begin{aligned} 50(4.53) \\
130(11.79)\end{aligned}$ & $\begin{array}{l}21(4.25) \\
41(8.30)\end{array}$ & 4.51 & 0.11 \\
\hline 84.85 & 923 (83.68) & $432(87.45)$ & & \\
\hline $\begin{array}{l}24.05 \\
20.16 \\
28.18 \\
27.61\end{array}$ & $\begin{array}{l}341(30.92) \\
184(16.68) \\
310(28.11) \\
268(24.29)\end{array}$ & $\begin{array}{c}43(8.70) \\
138(27.94) \\
140(28.34) \\
173(35.02)\end{array}$ & 14.92 & $<0.001$ \\
\hline $\begin{array}{l}41.08 \\
50.09 \\
0.88 \\
0.69 \\
7.26\end{array}$ & $\begin{array}{c}490(44.42) \\
513(46.51) \\
6(0.55) \\
7(0.63) \\
87(7.89)\end{array}$ & $\begin{array}{c}166(33.60) \\
287(58.10) \\
8(1.62) \\
4(0.81) \\
29(5.87)\end{array}$ & 25.44 & $<0.001$ \\
\hline $\begin{array}{l}35.38 \\
63.12 \\
1.5\end{array}$ & $\begin{array}{c}382(34.63) \\
705(63.92) \\
16(1.45)\end{array}$ & $\begin{array}{c}183(37.04) \\
303(61.34) \\
8(1.62)\end{array}$ & 2.14 & 0.71 \\
\hline $\begin{array}{l}90.61 \\
7.58 \\
0.81\end{array}$ & $\begin{array}{c}1034(93.74) \\
65(5.90) \\
4(0.36)\end{array}$ & $\begin{array}{c}429(86.84) \\
56(11.34) \\
9(1.82)\end{array}$ & 25.17 & $<0.001$ \\
\hline $\begin{array}{l}17.66 \\
13.21 \\
45.96 \\
23.17\end{array}$ & $\begin{array}{l}208(18.85) \\
177(16.05) \\
507(45.97) \\
211(19.13)\end{array}$ & $\begin{array}{c}74(14.98) \\
34(6.88) \\
227(45.95) \\
159(32.19)\end{array}$ & 4.96 & 0.17 \\
\hline $\begin{array}{c}8.14 \\
91.86\end{array}$ & $\begin{array}{c}84(7.62) \\
1019(92.38)\end{array}$ & $\begin{array}{c}46(9.31) \\
448(90.69)\end{array}$ & 1.73 & 0.42 \\
\hline $\begin{array}{l}12.46 \\
54.35 \\
22.67 \\
9.20 \\
1.31\end{array}$ & $\begin{array}{c}168(15.32) \\
639(57.93) \\
230(20.85) \\
53(4.82) \\
13(1.18)\end{array}$ & $\begin{array}{c}31(6.27) \\
229(46.36) \\
132(26.72) \\
94(19.03) \\
8(1.62)\end{array}$ & 111.51 & $<0.001$ \\
\hline
\end{tabular}

27.80

345 (31.28)

32.74

31.68

6.95

$381(34.54)$

323 (29.28)

$49(4.45)$

0.69

$5(0.45)$

$16.22 \quad 181(16.41)$

$64.93723(65.55)$

$19.04199(18.04)$

Page 14/16
99 (20.04)

$142(28.74)$

$183(37.04)$

62 (12.55)

8 (1.63)

75 (15.18)

$314(63.56)$

$105(21.26)$
$65.30<0.001$

2.29

0.32 


$\begin{array}{lccccc}\text { Self-compassion } & & & & \\ \quad \text { Low } & 90.11 & 989(89.66) & 450(91.09) & 45.24 & <0.001 \\ \quad \text { High } & 10.21 & 114(10.34) & 49(8.91) & & \\ \text { Resilience } & 51.70 & 560(50.77) & 266(53.85) & 13.70 & <0.001 \\ \quad \text { Low } & 48.30 & 587(49.23) & 184(46.15) & & \\ \quad \text { High } & 12.60 & 151(13.70) & 51(10.32) & 69.30 & <0.001 \\ \text { Social support } & 44.40 & 433(39.26) & 270(54.67) & & \\ \quad \text { Low } & 43.00 & 563(51.04) & 129(126.11) & & \\ \quad \text { Middle } & 94.18 & 1075(71.50) & 429(86.84) & 70.16 & <0.001 \\ \quad \text { High } & 5.82 & 28(30.10) & 65(13.16) & & \\ \text { Neuroticism } & 81.09 & 944(85.58) & 351(71.05) & 46.99 & <0.001 \\ \quad \text { Low } & 18.91 & 159(14.42) & 143(28.95) & & \\ \quad \text { High } & & & & \\ \text { Intensity of positive life events } & 68.25 & 811(73.53) & 279(56.48) & 45.77 & <0.001 \\ \quad \text { Low } & 31.74 & 292(26.47) & 215(43.52) & & \\ \quad \text { High } & & \end{array}$

Note: Abbreviations: BMI, body mass index; NG, normal group; RDG, risk for depression group.

TABLE 2 Scores for cognitive reactivity among Chinese young adults

\begin{tabular}{|c|c|c|c|c|c|c|c|c|}
\hline \multirow[t]{2}{*}{ Variables } & \multicolumn{3}{|c|}{$\operatorname{Total}(\mathrm{n}=1597)$} & \multicolumn{2}{|c|}{ NG $(n=1103)$} & \multicolumn{2}{|c|}{ RDG (n=494) } & \multirow[t]{2}{*}{$t$ value } \\
\hline & Total score & $\begin{array}{c}\text { Average } \\
\text { score }\end{array}$ & $\begin{array}{c}\text { Item } \\
\text { No }\end{array}$ & Total score & $\begin{array}{c}\text { Average } \\
\text { score }\end{array}$ & Total sc & $\begin{array}{c}\text { Average } \\
\text { score }\end{array}$ & \\
\hline $\mathrm{ACC}$ & $7.92 \pm 3.17$ & $1.98 \pm 0.79$ & 4 & $7.02 \pm 2.89$ & $1.76 \pm 0.72$ & $9.90 \pm 2.84$ & $2.48 \pm 0.71$ & $-18.40^{*}$ \\
\hline CTR & $10.32 \pm 3.96$ & $2.06 \pm 0.79$ & 5 & $8.46 \pm 2.87$ & $1.69 \pm 0.57$ & $14.46 \pm 2.74$ & $2.89 \pm 0.55$ & $-40.77^{*}$ \\
\hline AGG & $8.78 \pm 4.39$ & $1.76 \pm 0.88$ & 4 & $6.67 \pm 2.84$ & $1.67 \pm 0.57$ & $13.48 \pm 3.51$ & $3.37 \pm 0.50$ & $-38.50^{*}$ \\
\hline AVC & $15.69 \pm 6.00$ & $2.24 \pm 0.86$ & 7 & $12.75 \pm 4.13$ & $1.82 \pm 0.59$ & $22.25 \pm 4.02$ & $3.18 \pm 0.57$ & $-44.09^{*}$ \\
\hline HOP & $8.66 \pm 4.65$ & $1.73 \pm 0.93$ & 5 & $6.39 \pm 2.99$ & $1.28 \pm 0.60$ & $13.72 \pm 3.57$ & $2.74 \pm 0.71$ & $-40.49^{*}$ \\
\hline $\begin{array}{l}\text { Total } \\
\text { score }\end{array}$ & $51.36 \pm 18.97$ & $1.98 \pm 0.73$ & 26 & $41.30 \pm 11.80$ & $1.59 \pm 0.45$ & $73.82 \pm 11.07$ & $2.84 \pm 0.43$ & $-53.53^{*}$ \\
\hline
\end{tabular}

Note: Average score=total score/numbers of items; ${ }^{*} p<0.01$

Abbreviations: ACC, acceptance coping; AGG, aggression; AVC, avoidant coping; CTR, control/perfectionism; HOP, hopelessness/suicidality; NG, normal group; RDG, risk for depression group.

TABLE 3 The significant predictors of cognitive reactivity among Chinese young adults at risk for depression 


\begin{tabular}{|c|c|c|c|}
\hline Variable & $\mathrm{OR} / \operatorname{Exp}(\mathrm{B})$ & $p$-value & $95 \% \mathrm{CI}$ \\
\hline Residential location & & & \\
\hline Urban & Ref & & \\
\hline Rural & 0.54 & 0.04 & $0.34-0.85$ \\
\hline Employment status & & & \\
\hline Śtudents & Ref & & \\
\hline Full-time employment & 2.54 & $<0.01$ & $1.46-4.40$ \\
\hline Monthly household income(yuan) & & & \\
\hline$<1000$ & Ref & 0.03 & $050 \quad 07$ \\
\hline Frequency of sad mood in the past month & & 0.03 & $0.50-0.9$ \\
\hline $\begin{array}{l}\text { None } \\
\text { Always }\end{array}$ & $\begin{array}{l}\text { Ref } \\
4.29\end{array}$ & 0.04 & $1.96-9.08$ \\
\hline Sleep quality & & & \\
\hline $\begin{array}{l}\text { Very good } \\
\text { Bad }\end{array}$ & $\begin{array}{l}\text { Ref } \\
1.18\end{array}$ & 0.04 & $1.03-1.92$ \\
\hline Social support & & & \\
\hline $\begin{array}{l}\text { Low } \\
\text { High }\end{array}$ & $\begin{array}{l}\text { Ref } \\
0.58\end{array}$ & $<0.01$ & $0.43-0.78$ \\
\hline Self-compassion & & & \\
\hline $\begin{array}{l}\text { Low } \\
\text { High }\end{array}$ & $\begin{array}{l}\text { Ref } \\
0.14\end{array}$ & 0.001 & $0.05-0.71$ \\
\hline Neuroticism & Ref & & \\
\hline High & 6.66 & $<0.01$ & $1.41-3.33$ \\
\hline Resilience & & & \\
\hline $\begin{array}{l}\text { Low } \\
\text { High }\end{array}$ & $\begin{array}{l}\text { Ref } \\
0.63\end{array}$ & $<0.01$ & $0.47-0.86$ \\
\hline $\begin{array}{l}\text { Intensity of negative life events } \\
\text { Low } \\
\text { High }\end{array}$ & $\begin{array}{l}\text { Ref } \\
1.49 \\
\end{array}$ & 0.01 & $1.12-2.00$ \\
\hline
\end{tabular}

Note: Abbreviations: CI, confidence interval; OR, odds ratio; Ref, reference. 